\title{
Evaluation of patch tests results - development of technique based on infrared thermography
}

\author{
by B. Tomaka*, M. Szwedo**, J. Targosz*
}

* AGH University of Science and Technology, 30 Mickiewicza Av., 30-059 Kraków, Poland, tomaka@agh.edu.pl ** MONIT SHM Sp. z o.o., 34 Lublańska Str., 31-476 Kraków, Poland, mszwedo@monitshm.pl

\begin{abstract}
Infrared thermography is not commonly used in dermatological and allergological diagnostics, but as a noninvasive, non-contact and relatively cheap measurement technique may be a valuable tool for future interpretation of various medical examination results. In our research we focus on application of infrared thermography for evaluation of patch test results used in contact dermatitis diagnostics. We develop and test the procedure of data acquisition for tests performed on patients, which allows to check the difference in skin temperature at regions where patch tests were incubated in comparison to the neighbouring skin regions and reference temperature.
\end{abstract}

\section{Introduction}

Infrared thermography is not commonly used in dermatological and allergological diagnostics, but as a noninvasive, non-contact and relatively cheap measurement technique may be a valuable tool for future interpretation of various medical examination results so scientists keep interested in developing the technique. For example Laino et al. [1] described problems with hot areas that extended beyond the borders of the patch site. They have pointed out the necessity to keep large intervals between patches, like 8 to $10 \mathrm{~cm}$. In the study of Dencheva et al. [2] they acquired $100 \%$ matching of clinical and thermal image results for negative skin reaction and $60,7 \%$ for positive.

Generally skin tests are used in allergological diagnosis and its principle is to attempt to provoke a small, controlled, allergic response. Allergic reactions occur when a person's immune system reacts to allergens, which are normally harmless substances in the environment. In case of patch tests this reaction results in an inflammatory response caused by a type-IV cell-mediated reaction with release of proinflammatory cytokines increase permeability of blood vessels and with typical local symptoms like redness, temperature increase and eczema with erythema, papules, vesicles and weeping. This inflammatory lesions can spread beyond the area of contact to other part of the body, often in a symmetrical pattern [3]. Allergic contact dermatitis (ACD) lesions usually appear 24-48 hours after the last exposure to the allergen and reach their peak at approximately 72-96 hours, but they may develop as early as 5 hours or as late as 7 days after exposure [4]. Patch testing is the only useful and reliable method for identification of an allergic contact dermatitis - it is acknowledged as the gold standard. Evaluation of the test does concern only skin surface because it depends on visual assessment. Thus difficulties like changes in skin pigmentation, atopic skin, black race skin or delayed reaction may occur and as a result it cannot be treated as an objective method. Common problem occurring during patch test results evaluation is connected with interpretation of lesions as irritant, doubtful and weak reaction, especially at second reading, when uncertain grades are not allowed. The issue is that in case of negative grade at second reading it matters if interpretation of reaction at first reading was either doubtful $(+/-)$ or weak $(+)$. Wrong diagnostics extends time of final diagnosis, generates costs by necessity of another physical and causes discomfort of the patient.

In our research we focus on application of infrared thermography for evaluation of patch test results. We develop the procedure of data acquisition for tests performed on patients, which allows to check the difference in skin temperature at regions where patch tests were incubated in comparison to the neighbouring skin regions and reference temperature.

\section{Screening protocol}

The proposed screening protocol starts from acclimatization, firstly patient should come calmly and for 15 to 30 minutes stay in rest at waiting room and after that wait for 5-30 minutes at consulting room with uncovered areas which are to be examined. Then the sequence of images is registered and after geometrical calibration obtained images will be overlapped for more precise analysis in ThermoAnalysis software, among other things with use of Pulsed Phase Thermography (PPT) to precise recover the gradient distribution of the thermal changes. Next stage is comparison of images from each readings and classification of lesions. Results obtained after that process are compared with physician evaluation and saved to the data base. In Fig. 2 the procedure of IR thermography medical imaging acquisition and analysis is presented. The procedure is performed during standard reading made by a physician, twice for each patient, first time after 48 hours from patch application (after patch removal) and second time after 96 hours from patch application. 


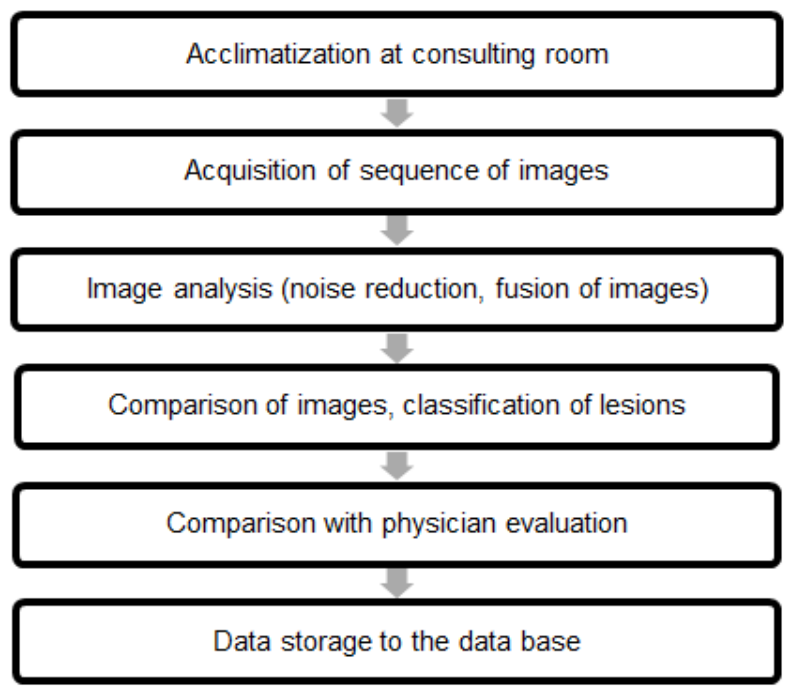

Fig. 1. The procedure of IR thermography medical imaging acquisition and analysis

In reference to results of our primary tests described in [5], where results obtained with use of infrared thermography were valuable and promising but not obvious, we are developing the procedure of data acquisition. Although measurement conditions were almost the same, it was difficult to compare obtained thermographs so we implemented a reference temperature module for our measurement stand.

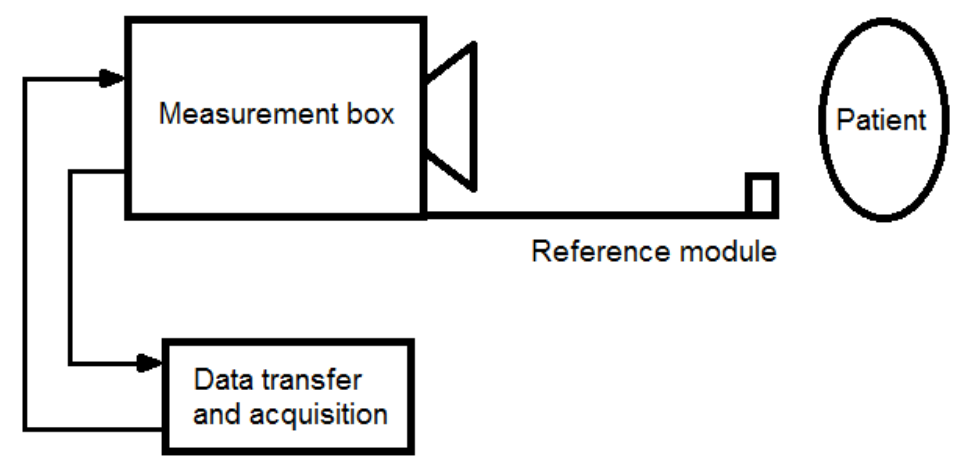

Fig. 2. Schematic of measurement unit

To obtain better diagnostic results with reduced patient discomfort during medical examination we developed dedicated measurement stand. Schematic of prototype system for patch tests evaluation is presented at Fig. 2. It consist of measurement box with reference module and mobile computer for image acquisition and control of measurement parameters. Inside measurement box we have placed: infrared camera FLIR A300, industrial camera Allied Vision Mako, system of lights and power supply unit with programmable digital microcontroller ATmega16. FLIR A300 is equipped in a standard uncooled microbolometer FPA with resolution 320x240 pixels and image frequency $30 \mathrm{~Hz}$. Vision camera, made in CMOS technology, has resolution 2048x1088 pixels and wide spectral range. Application of this two types of cameras will enable image correlation between the visual and thermal images. System of lights is required for vision camera and in that usage it is a set of lights with different wavelength to improve detection of lesions. Phase lock of cameras and synchronization with lights is controlled by programmable digital microcontroller ATmega16 in correlation with ThermoAnalysis software (MONIT SHM Sp. z o.o.). As a reference module we used a Peltier module (12V, 60W) settled in our measurement stand in the way that it is positioned near examined object and is in the IR camera field of view. Used in tests Peltier modulus supplied with $3 \mathrm{~V}$ attains stable temperature after less than 3 minutes so it will not elongate the preparation procedure and it gives opportunity to compare images from different readings of the same patient as well as different patients. The measurement is made at distance around 80 centimetres from the patient and it does not have any special requirement to operate, so it is possible to use it even in a small consulting room which meets the criteria which are obligatory in medical thermography. Those criteria are as follows: ambient temperature within $20-$ $23^{\circ} \mathrm{C}$, air humidity within $45-55 \%$, lack of external heat and radiation sources, no draught and enough space. It was defined to provide better accuracy and repeatability of the measurements [6].

For proper thermal analysis it is important that the tissue is non-homogenous medium with non-linear, temperature and time dependent thermal properties. Temperature distribution in tissues depends on few parameters, like thermal conductivity, convection heat transfer, metabolic heat production, external heat transferred to the tissue, time, 
tissue's geometry. Pennes [12] suggested that the rate of heat transfer between blood and tissue is proportional to the product of volumetric perfusion rate and the difference between the arterial blood temperature and the local tissue temperature. It is expressed by Eq. (1)

$$
Q_{b}=V \rho_{b} C_{b}(1-\kappa)\left(T_{a}-T\right)
$$

where: $Q_{b}\left[\mathrm{~W} / \mathrm{m}^{3}\right]$ - rate of heat transfer per unit volume of tissue, $\rho_{b}-$ density of blood, $C_{b}-$ specific heat of blood, $k-$ factor that accounts for incomplete thermal equilibrium between blood and tissue, $T_{a}$ - temperature of arterial blood, $T$ local tissue temperature.

Following Eq. (1) the thermal energy balance for perfused tissue is as shown at Eq. (2)

$$
\rho C \frac{\partial T(x, y, z, t)}{\partial t}=k \nabla^{2} T(x, y, z, t)+Q_{b}+Q_{m}
$$

where: $C$ - specific heat, $\rho$ - density of tissue, $k$ - thermal conductivity of tissue, $T(x, y, z, t)[\mathrm{K}]-$ temperature at time $t, Q_{m}$ - rate of metabolic heat production per unit volume of tissue.

According to $[9,10,11]$ the essence of the thermography is to compare temperature of the skin with positive reaction to allergen with temperature of surrounding healthy skin, so information about gradient of temperature is more important than its absolute value. Emissivity of biological tissues is within 0.85 and 0.98 . For human skin it is reported to be equal $0.98 \pm 0.01$ for wavelength range of $2-20 \mu \mathrm{m}$, it peaks around $10 \mu \mathrm{m}$, regardless of skin colour. Generally, for medical applications narrower wavelength band is used, from 8 to $12 \mu \mathrm{m}$. Maximal gradient for the strongest allergic reactions is within 2 and $3^{\circ} \mathrm{C}$ (accuracy of measurement depends on parameters of used camera).

\section{Results}

After our primary tests described in [5], we had performed tests using designed measurement stand. Fig. 3, Fig. 4 and Fig. 5 shows results obtained during initial tests.
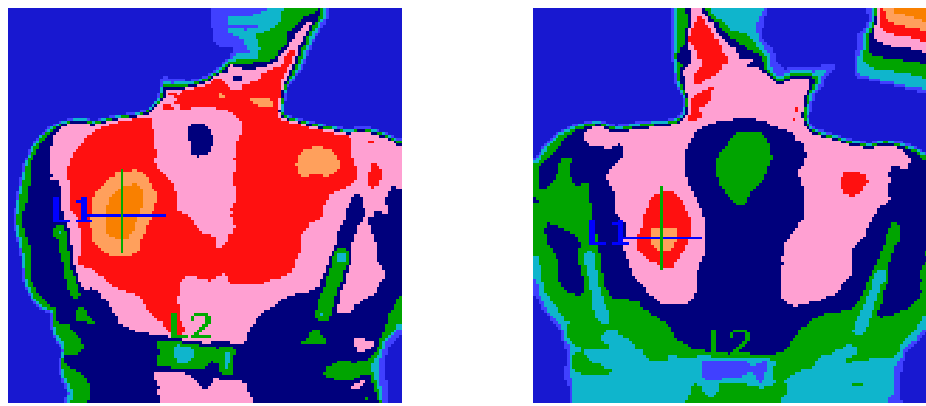

Fig. 3. Initial tests - example of extreme reaction. Thermograph after: 2 days (left) and 4 days (right)
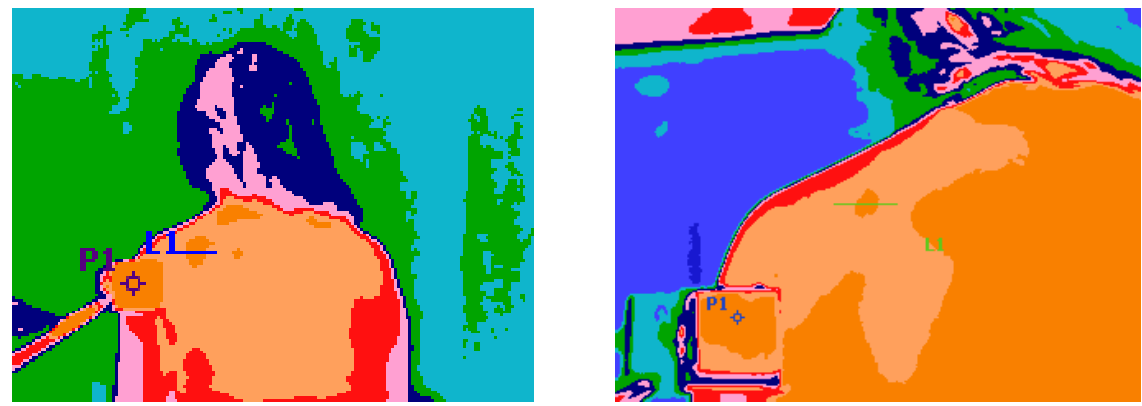

Fig. 4. Initial test with reference temperature at point $P 1$ - example of positive reaction to allergen. Thermograph after: 2 days (left) and 4 days (right) 

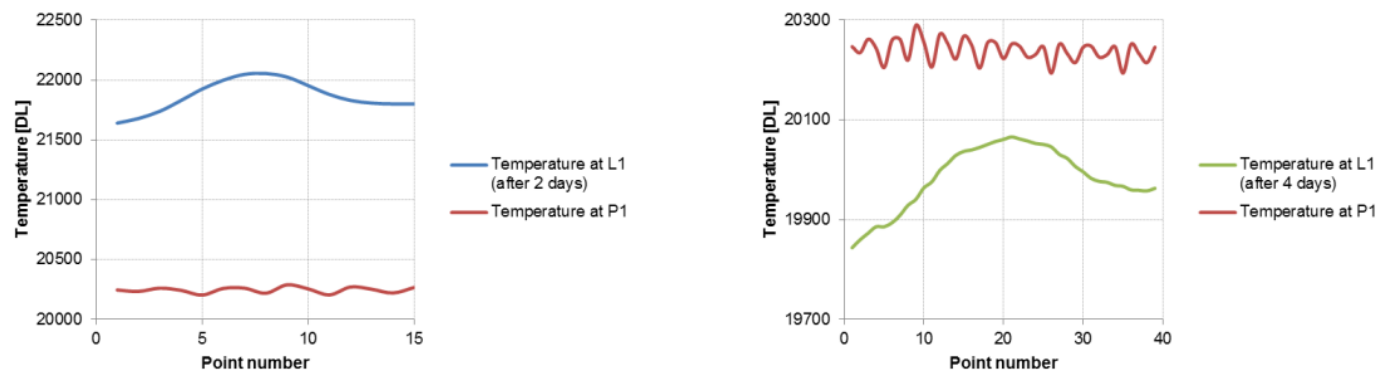

Fig. 5. Initial test with reference temperature at point $P 1$ - example of positive reaction to allergen. Temperature changes (in digital units) at $L 1$ and $P 1$ after: 2 days (left) and 4 days (right)

Results presented in Fig. 4 and Fig. 5 shows that usage of reference temperature module makes possible to compare images acquired at different time by proper camera calibration and unification of the values of the histograms. For tests performed on patients it allows to check the difference in skin temperature at regions where patch tests were incubated in comparison to the neighbouring skin regions and reference temperature. This allows to become independent of the changing measurement conditions during individual measurement sessions.

Next step in our development was to evaluate presented diagnostic procedure during standard patch tests performed on patients with usage of our measurement stand and advanced imaging analysis.
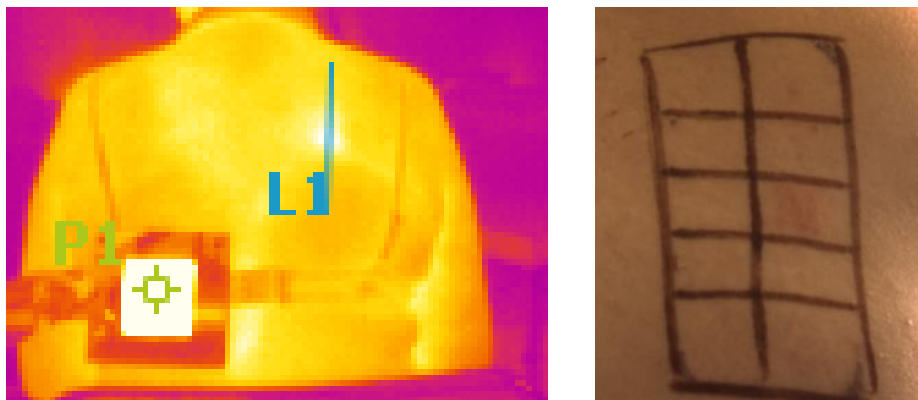

Fig. 6. Thermograph with reference temperature at point $P 1$ - example of strong positive reaction to allergen

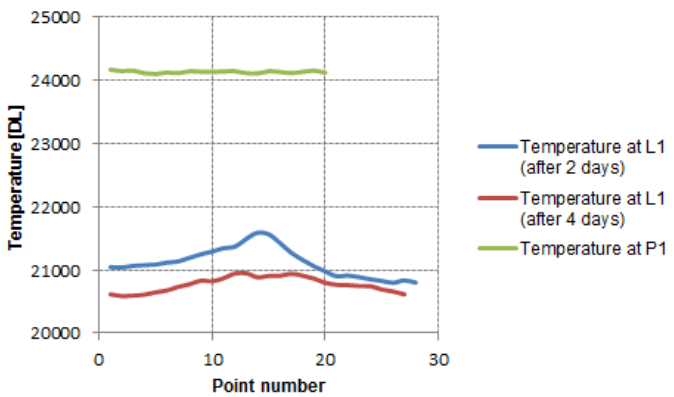

Fig. 7. Test with reference temperature at point $P 1$ - example of strong positive reaction to allergen. Temperature changes (in digital units) at $L 1$ and $P 1$ after: 2 days and 4 days

The inflammatory reaction to allergen presented in Fig. 6 and Fig. 7, where examined patient had positive reaction which appeared at first reading as strong one, is well visible both thermograph and photograph. Maximum temperature at line $\mathrm{L} 1$ after 2 days is $35.2^{\circ} \mathrm{C}$ while minimum is $31.5^{\circ} \mathrm{C}$, so the difference is $3.7^{\circ} \mathrm{C}$. After 4 days maximum temperature is $32.8^{\circ} \mathrm{C}$ while minimum is $30.3^{\circ} \mathrm{C}$, so the difference is equal $2.5^{\circ} \mathrm{C}$. 

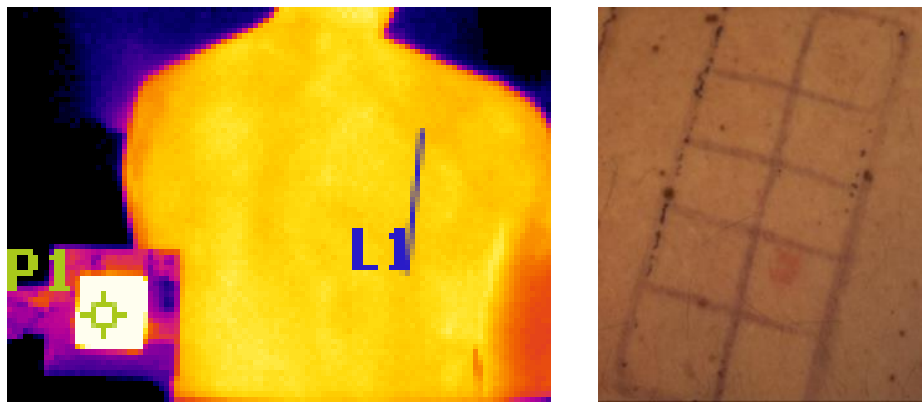

Fig. 8. Thermograph with reference temperature at point $P 1$ - example of weak positive reaction to allergen

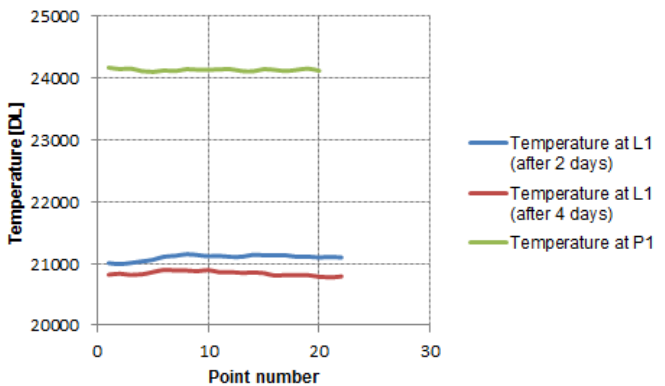

Fig. 9. Test with reference temperature at point $P 1$ - example of weak positive reaction to allergen. Temperature changes (in digital units) at $L 1$ and $P 1$ after: 2 days and 4 days

Fig. 8 and Fig. 9 shows weak inflammatory reaction to allergen, where examined patient had negative reaction at first reading and positive at second reading. Thermal reaction is slightly visible in the thermograph and the temperature changes at $\mathrm{L} 1$. Maximum temperature at line $\mathrm{L} 1$ after 2 days is $34^{\circ} \mathrm{C}$ while minimum is $32.7^{\circ} \mathrm{C}$, so the difference is $1.3^{\circ} \mathrm{C}$. After 4 days maximum temperature is $32.4^{\circ} \mathrm{C}$ while minimum is $31.3^{\circ} \mathrm{C}$, so the difference is equal to $1.1^{\circ} \mathrm{C}$.

\section{Conclusions}

Medical thermal image processing is a field of study which should be developed in the future, because it may significantly improve skin tests assessment. It is promising and as additional method may help to increase the percentage of properly diagnosed patients in allergology. Furthermore, usage of our measurement unit gives opportunity to compare images with results from different readings of the same patient as well as different patients. The ability to view historical data can be helpful for physicians especially during evaluation of ambiguous cases. However, the measurement procedure still needs to be tested, because slight temperature differences might be overlooked or misinterpreted (if acclimatization rules are not kept), and developed to make the visualisation of the results more obvious for physicians.

For further research it is planned to create network-centric system to store the thermographs with physician description (diagnosis), case record, diagnostic results and description parameters. Those thermal images will be classified according to type of diagnosed pathology.

\section{Disclosure statement}

No potential conflict of interest was reported by the authors.

\section{REFERENCES}

[1] Laino L., di Carlo A., "Telethermography: an objective method for evaluating patch test reactions", Dermatology, vol. 20 , No. 2, pp. $175-180,2010$

[2] Dencheva M., Lyapina M., Kisselova A., et al., "Thermovision in dental allergology", Journal of IMAB, vol. 20, issue 3, pp. 558-562, 2014.

[3] Streit M., Braathen L. R., "Contact dermatitis: clinics and pathology", Acta Odontol Scand, vol. 59, pp.309-314, 2001.

[4] Iris Ale S., Maibach H. I., „Irritant contact dermatitis versus allergic contact dermatitis”, Irritant Dermatitis, Chapter 2, pp. 11-18, 2006.

[5] Szwedo M., Tomaka B., "Evaluation of patch tests results - research and development of technique based on infrared thermography”, Diagnostyka, ISSN 1641-6414, vol. 16 no. 3, pp. 3-8, 2015. 
[6] Lahiri B.B., Bagavathiappan S., Jayakumar, Philip J., "Medical applications of infrared thermography: A review", Infrared Physics \& Technology, vol. 55, pp. 221-235, 2012.

[7] Fonacier L., Bernstein D., Pacheco K., et al., "Contact dermatitis: a practice parameter-Update 2015", Journal of Allergy and Clinical Immunology: In Practice, vol. 3 no. 3S, 2015. (https://www.aaaai.org/Aaaai/media/MediaLibrary/PDF\%20Documents/Practice\%20and\%20Parameters/Contac t-dermatitis-2015.pdf)

[8] Szentkuti A., Kavanagh H.S., Grazio S., "Infrared thermography and image analysis for biomedical use", Periodicum biologorum, vol. 113, no 4, pp. 385-392, 2011.

[9] Lahiri B.B., Bagavathiappan S., Jayakumar, Philip J., "Medical applications of infrared thermography: A review", Infrared Physics \& Technology, vol. 55, pp. 221-235, 2012.

[10] Laino L., di Carlo A., "Telethermography: an objective method for evaluating patch test reactions", Dermatology, vol. 20, No. 2, pp. 175-180, 2010.

[11] Szentkuti A., Kavanagh H.S., Grazio S., "Infrared thermography and image analysis for biomedical use", Periodicum biologorum, vol. 113, no 4, pp. 385-392, 2011.

[12] Pennes H.H., "Analysis of tissue and arterial blood temperatures in the resting human forearm", J. Appl. Physiol., 1:93-122, 1948.

[13] Ring E.F.J., Ammer K., "Infrared thermal imaging in medicine", Physiological Measurement, vol. 33, pp. R33$\mathrm{R} 46,2012$

[14] ISO/TR 13154:2009 Medical electrical equipment-deployment, implementation and operational guidelines for identifying febrile humans using a screening thermograph

[15] IEC 80601-2-59:2008, Ed. 1.0 Medical electrical equipment-part 2-59: particular requirements for the basic safety and essential performance of screening thermography for human febrile temperature screening

[16] Chen M.M., Holmes K.R., "Microvascular contributions in tissue heat transfer", Ann. N.Y. Acad. Sci. 335, pp. 137-150, 1980.

[17] Diakides N.A., Bronzino J.D., ed., "Medical Infrared Imaging”, CRC Taylor\&Francis, 2008. 